known to be not exclusively arrhenotokously or thelytokously parthenogenetic ${ }^{2}$. It is evident that the biology of saw-flies will well repay further study.

Thanks are due to Prof. A. D. Peacock, under whose supervision I have worked, for the provision of certain material: to Dr. Ann R. Sanderson, for the benefit of her experience in similar work; and to Mr. A. T. Baxter for laboratory assistance.

University College, Dundee,

Lesime C. Comrie.

University of St. Andrews.

${ }^{1}$ Doncaster, L., Quart. J. Micr. Sci., 49 (1906) and 51 (1907).

Peacock, A. D., Tijdsch. v. Entomologie, 81 (1938).

\section{Nitrogen Fixation by Blue-Green Algæ}

Is India, rice is grown on the same land for many years without the addition of manures to the soil. Preliminary experiments have shown that a considerable amount of nitrogen is fixed in the soils of the rice-fields under water-logged conditions, when there is an abundance of algal growth (especially Blue-green Algæ) present. With the object of investigating the role of the Blue-green Algæ, a number of species of Anabona, as well as Phormidium foveolarum, were isolated in unialgal culture from the soil of an Indian rice-field. The last, as well as three species of Anabcena, were afterwards obtained in pure culture, altogether devoid of bacteria and other contaminating organisms, by a method analogous to that employed by Pringsheim (1913). These cultures have been tested by the Bacteriological Department at the Rothamsted Experimental Station and pronounced free from bacteria.

Inoculations from these pure cultures, grown in mineral solutions lacking nitrogen (apart from that contained in minute traces of soil-extract), showed that, while the Phormidium has no capacity for fixation of nitrogen, the three species of Anabcena are able to fix considerable quantities, averaging 3-5 mgm. of nitrogen per 100 c.c. of medium in about two months. The amount of nitrogen fixed by the Algæ in the presence of Azotobacter and other bacteria is the same as in the pure cultures, from which it appears that bacteria play a relatively unimportant part in nitrogen fixation in the rice-fields.

The effect of the presence of various organic compounds on the process has been examined. Certain soluble carbohydrates (arabinose, maltose, raffinose, inulin and dextrin) have a decidedly inhibiting effect on nitrogen fixation; but the process will go on in the presence of soluble nitrogen compounds. Iron is not essential for nitrogen fixation.

Diverse workers (Molisch 1926, Vouk and Wellisch 1931, Copeland 1932) have previously affirmed nitrogen fixation by Blue-green Algæ, but the evidence as to the purity of their cultures is not adequate. Drewes (1928) and Winter (1935) used several bacteriological agar media to test the purity, but the evidence is inconclusive, since on such media, in the presence of Algæ, there may be no visible growth of bacteria although present. A similar criticism applies to the researehes of Allison and co-workers (1932 and 1935).

F. E. Fritsch.

P. K. DE.

Queen Mary College,

Mile End Road,

London, E.1.

Oct. 14.

\section{Normal Dentition of Sharks}

WHEN the teeth of the various rows in the jaw of Carcharias melanopterus at different ages are compared, one observes an exposed row of teeth slightly smaller than the unerupted ones behind it, and incomplete hindermost rows of what appear to be vestigial remains of teeth which can never come into use. Mr. G. P. Whitley, of the Australian Museum, has kindly referred me to Gudger and Smith's memoir ${ }^{1}$ on "the most primitive shark", Chlamydoselachus, and notes "unfortunately the problem of their replacement has not been touched upon, else considerable light might have been thrown on the matter. From fossil sharks too there are no apparent data on this point".

In this memoir, which I have seen from the South African Museum, the small teeth of Chlamydoselachus are regarded as employed for retaining the food that is seized, rather than for chopping off pieces like the broad teeth of Charcharodon and Galeocerdo.

If the exposed teeth of these latter were constantly shed and replaced from the unerupted teeth, one would expect to find in an adult the largest teeth exposed or lacking in serration through constant use.

$$
\begin{aligned}
& \text { Britannia Buildings, F. G. CAwston. } \\
& \text { West Street, } \\
& \text { Durban. } \\
& \text { "Gudger, E. W., and Smith, B. G., "Natural History of the Frilled } \\
& \text { Shark, Chlamydoselachus anguineus", Bashford Dean Memorial }
\end{aligned}
$$
Volume, Art. 5, No. 23, 277 (1933).

\section{Mesotron (Intermediate Particle) as a Name for the New Particles of Intermediate Mass}

THE existence of particles intermediate in mass between protons and electrons has been shown in experiments on the cosmic radiation ${ }^{1}$. Since at present so little is known concerning the properties of these particles, for example, the exact value of the mass, the laws governing their production, their stability against disintegration, ete., it may yet be too early to assign to them a name. But inasmuch as several names have already been suggested, namely, dynatron, penetron, barytron, heavy electron, yukon and $x$-particle, it may be wise to consider the matter at this time.

The property which so far serves to distinguish the new particles from the other two types of particles which carry the same magnitude of electric charge, namely, the proton and the electron, seems to be the magnitude of their mass. Although from the experiments so far performed, it is not possible to say definitely whether the new particles exist with a unique mass only, or whether they occur with a range of masses, it does appear quite certain that the mass, whether unique or not, is greater than that of an electron and less than that of a proton. One must consider then three types of particles all carrying electric charges of equal magnitude: electrons, the new particles and protons. We should like to suggest therefore the word 'mesotron' (intermediate particle) as a name for the new particles. It appears quite likely that the appropriateness of this name will not be lost, whatever new facts concerning these particles may be learned in the future.

Carl D. Anderson.

SETH H. NEDDERMEYER.

California Institute of Technology,

Pasadena. Sept. 30.

1 For historical summary see Wentzel, G., Naturuiss., 26, 273 (1938); and Bowen, Millikan and Neher, footnote, Phys. Rev., 58, 219 (1938). 